\title{
Percutaneous lung needle biopsies - utility and complications in various chest lesions: a single-institution experience
}

\author{
Małgorzata Jelitto-Gorska ${ }^{1 A, C, E,}$, Michał Studniarek ${ }^{20, F}$, Agata Durawa ${ }^{3 B, F}$, Tomasz Marjanski $^{40 E}$, Edyta Szurowska ${ }^{1 \mathrm{~A}}$ \\ 'Second Department of Radiology, Medical University of Gdansk, Poland \\ ${ }^{2}$ First Department of Radiology, Medical University of Gdansk, Poland \\ ${ }^{3}$ University Medical Centre of Gdansk, Poland \\ ${ }^{4}$ Department of Thoracic Surgery, Medical University of Gdansk, Poland
}

\section{Abstract}

Purpose: It is crucial to obtain a specific diagnosis before treatment of chest pathology is initiated. The purpose of the study is to present the utility of percutaneous biopsies, core and fine-needle aspiration, in various thoracic lesions, and related complications.

Material and methods: A total of 593 transthoracic biopsies were performed in the Department of Radiology between 2013 and 2016. Fine-needle aspiration biopsy (FNAB) and core biopsy (CB) were implemented. The procedures were divided into four groups according to the location of the pathology: lung lesions ( $L L-540)$, mediastinal masses $(\mathrm{MM}-25)$, chest wall tumours (CWT - 13), and pleural lesions (PL - 15). The lung lesion group was divided into two subgroups: lung nodules and lung infiltrations. All groups were analysed in respect of diagnostic accuracy, pathological findings, and complication rate.

Results: Pathological diagnosis was confirmed in 447 cases after all 593 procedures. The sensitivity of malignancy diagnosis in the group of lung tumours was $75 \%$ for FNAB and $89 \%$ for CB. The sensitivity in other groups, where CB was a preferable technique, was counted for lung infiltration, mediastinal masses, chest wall tumours, and pleural lesions and amounted to $83.3 \%, 90.9 \%, 100 \%$, and $85.7 \%$, respectively. In the group of lung tumours malignancy was confirmed most commonly $(79 \%)$, while in the lung infiltration group benign processes dominated $(83 \%)$. There was no statistical difference between the pneumothorax rate after CB and FNAB. Haemoptysis appeared more often after CB.

Conclusions: FNAB and CB are useful, safe, and sensitive tools in the diagnostic work-up. They can both be used to diagnose almost all chest pathologies.

Key words: computed tomography, needle biopsy, chest pathology.

\section{Introduction}

To obtain a definite diagnosis of chest pathology is not an easy task. Groups of pulmonary nodules, lung infiltrations, and other chest pathologies comprise a variety of malignant and benign lesions that are difficult to differentiate with use of radiological investigation [1].

In numerous studies investigators have evaluated the usefulness of transthoracic needle biopsy in the diagnostic work-up of lung parenchymal lesions [2-4], but only a few studies have elaborated this diagnostic tool for chest wall tumours, mediastinal masses, or pleural lesions [5-7]. Both fine-needle aspiration and core biopsy have high diagnostic accuracy with acceptable complication rates [8,9]. The purpose of the study is to present the diagnostic accuracy, pathological findings, and risk of complications connected with the aspiration or core transthoracic needle biopsy in various chest pathologies.

Correspondence address:

Małgorzata Jelitto-Górska, MD, 36 Kalinowa St., 80-177 Gdańsk, Poland, phone: +48 793211 622, e-mail: jelitto@gumed.edu.pl

Authors' contribution:

A Study design · B Data collection · C Statistical analysis · D Data interpretation · E Manuscript preparation · F Literature search · G Funds collection 


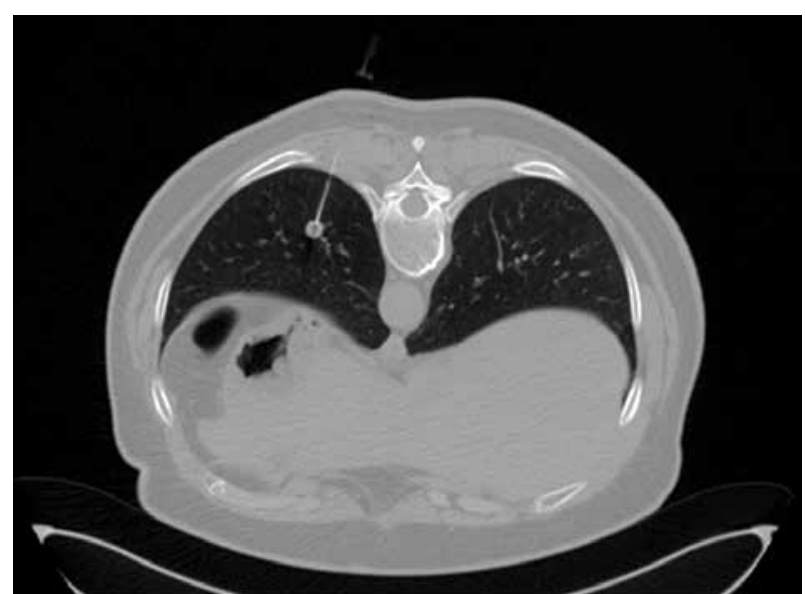

Figure 1. An example of lung tumour biopsy - typical carcinoid was confirmed

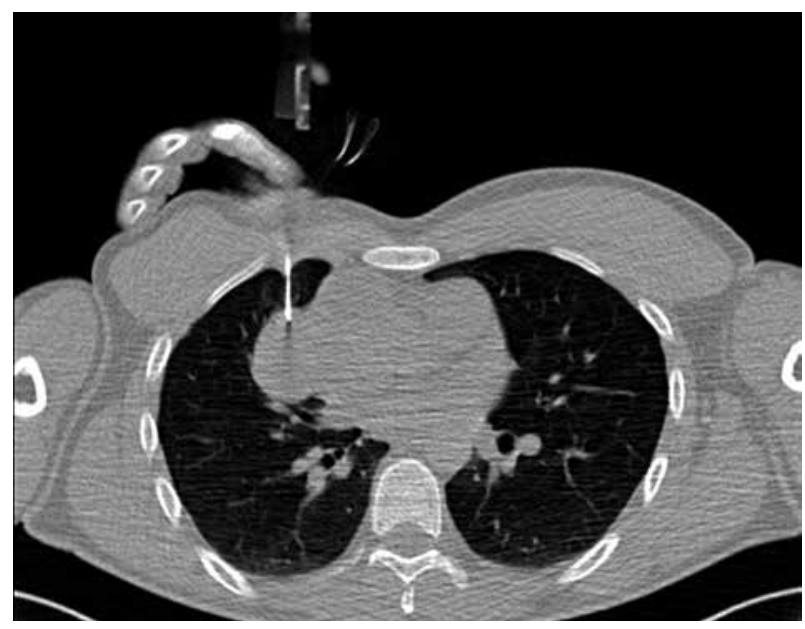

Figure 3. An example of mediastinal mass biopsy in a male patient primary mediastinal choriocarcinoma was confirmed

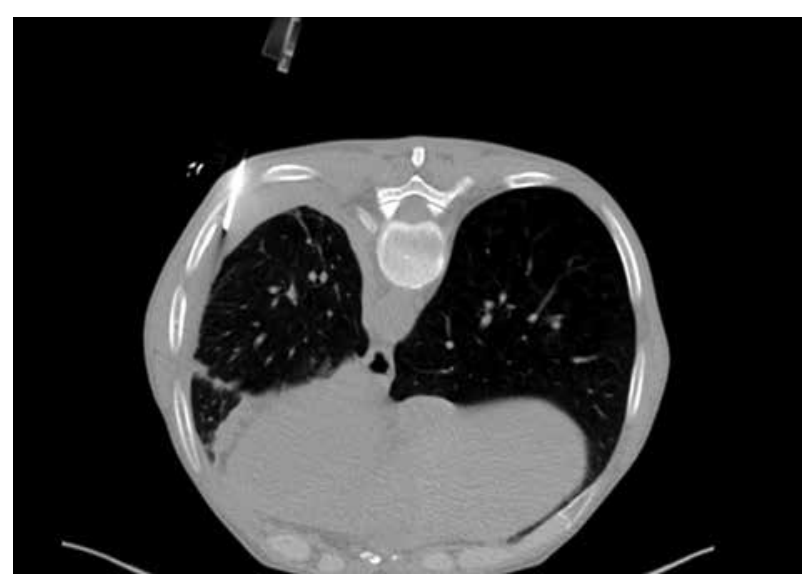

Figure 5. An example of pleural lesion biopsy - pathological evaluation confirmed mesothelioma

\section{Material and methods}

A total of 593 transthoracic biopsies were performed between April 2013 and August 2016 in our Radiology Department by the same radiologist. We present a retrospective analysis of the procedures.

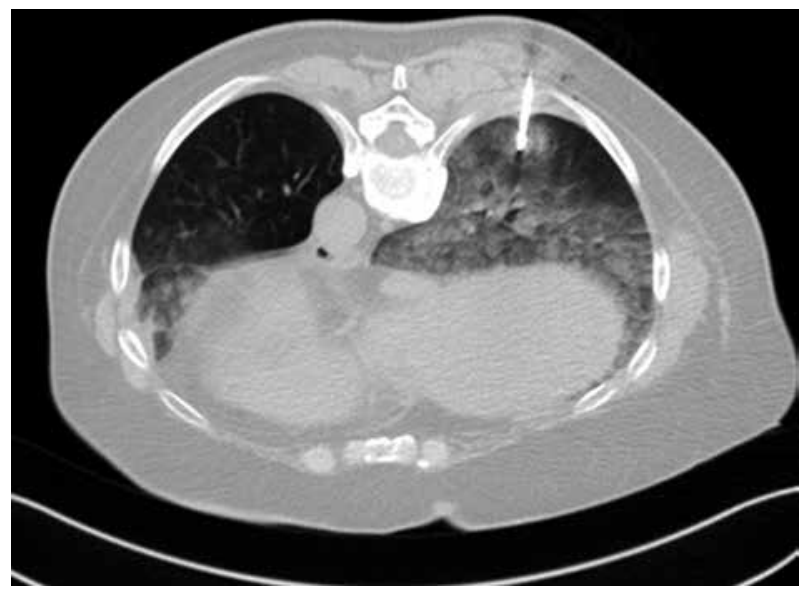

Figure 2. An example of lung infiltration biopsy - pulmonary adenocarcinoma was confirmed

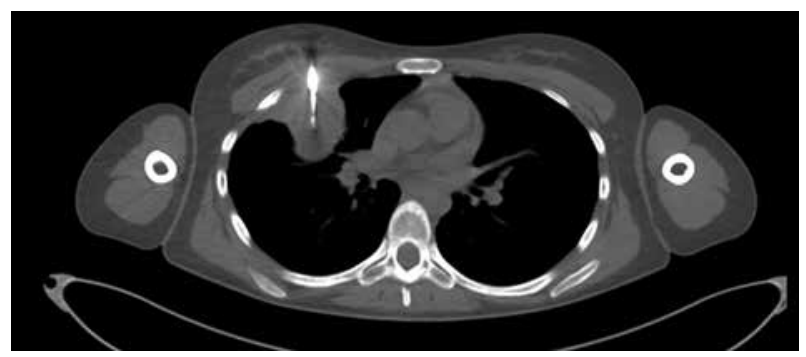

Figure 4. An example of chest wall tumour biopsy - Ewing sarcoma was confirmed

All biopsies were performed computed tomography (CT)- or CT-fluoroscopy-guided and were performed using a 128-row CT scanner.

Fine-needle aspiration biopsy (FNAB) or core biopsy (CB) were performed.

Before the procedure, informed consent was obtained in all cases. A $1 \%$ solution of lidocaine was used as local anaesthesia.

All performed procedures were divided into four groups according to the location of the pathology:

- lung lesions (LL) - 540 procedures: all intraparenchymal lesions with probable lung parenchyma origin (including lung lesions infiltrating the mediastinum, pleura, or chest wall), subdivided into:

- lung tumours: well-defined nodules with sharp, definite margins separating them from healthy lung parenchyma,

- lung infiltration: ill-defined lesions without sharp borders, which infiltrate lung parenchyma;

- mediastinum masses (MM) - 25 procedures: both mass or lymph nodes located originally in the mediastinum (bone or pleural lesions with mediastinal involvement were excluded from this group);

- chest wall tumours (CWT) - 13 procedures: masses with probable origin within chest wall structures such as ribs and muscles (lung tumours with chest wall involvement were excluded from this group);

- pleural lesions (PL) - 15 procedures: pathologies located within or between parietal and visceral pleura 
Table 1. Biopsy details for various groups of pathologies

\begin{tabular}{|l|c|c|c|c|c|c|c|c|c|c|c|}
\hline & $\begin{array}{c}\text { Lung } \\
\text { tumours }\end{array}$ & 506 & $\begin{array}{c}\text { Lung } \\
\text { infiltration }\end{array}$ & 34 & $\begin{array}{c}\text { Mediastinal } \\
\text { masses }\end{array}$ & 25 & $\begin{array}{c}\text { Chest wall } \\
\text { tumours }\end{array}$ & 13 & $\begin{array}{c}\text { Pleural } \\
\text { lesions }\end{array}$ & 15 \\
\hline Size (mm) & 27.2 & & & 41.2 & & 55.2 & & 44.3 & \\
\hline \begin{tabular}{l} 
Biopsy details \\
\hline FNAB (22-gauge)
\end{tabular} & 214 & $42.3 \%$ & 2 & $5.9 \%$ & 4 & $16 \%$ & 0 & $0 \%$ & 0 & $0 \%$ \\
\hline Use of CT fluoroscopy & 4 & $1.9 \%$ & 0 & $0 \%$ & 2 & $50 \%$ & & & & \\
\hline CB & 292 & $57.7 \%$ & 32 & $94.1 \%$ & 21 & $84 \%$ & 13 & $100 \%$ & 15 & $100 \%$ \\
\hline 12 -gauge & 4 & $1.3 \%$ & 1 & $3.1 \%$ & 0 & $0 \%$ & 3 & $23 \%$ & 2 & $13 \%$ \\
\hline 14 -gauge & 48 & $16.5 \%$ & 9 & $28.1 \%$ & 1 & $4.8 \%$ & 7 & $53.8 \%$ & 4 & $27 \%$ \\
\hline 16 -gauge & 87 & $29.9 \%$ & 16 & $50 \%$ & 15 & $71.4 \%$ & 2 & $15.4 \%$ & 6 & $40 \%$ \\
\hline 18 -gauge & 149 & $51 \%$ & 6 & $18.8 \%$ & 5 & $23.8 \%$ & 1 & $7.7 \%$ & 3 & $20 \%$ \\
\hline 20 -gauge & 4 & $1.3 \%$ & 0 & $0 \%$ & 0 & $0 \%$ & 0 & $0 \%$ & 0 & $0 \%$ \\
\hline Use of CT fluoroscopy & 165 & $60.8 \%$ & 0 & $0 \%$ & 18 & $85.7 \%$ & 3 & $23 \%$ & 3 & $20 \%$ \\
\hline
\end{tabular}

FNAB - fine-needle aspiration biopsy, CT - computed tomography, CB - core biopsy

(lung tumours with pleural infiltration were excluded from this group).

Examples of lesions from separate groups are presented in Figures 1-5. For each group specific information such as pathological outcomes, sensitivity, and complication rate is provided.

As regards complications, we noted that all (even the smallest) areas of pneumothorax were visualised in the follow-up X-ray the next day after the procedure. Also, we analysed the pneumothorax in respect of whether chest tube insertion was needed or not. Pneumothorax requiring chest drainage was defined as any symptomatic pneumothorax (pain and/or dyspnoea) or pneumothorax surrounding the entire lung on plain PA chest X-ray. The decision was undertaken by a board-certified thoracic surgeon.

We also noted any alveolar haemorrhages that appeared in follow-up CT scan both with or without further haemoptysis. We recorded all cases of blood spitting observed after the procedure, including minor spitting without the need for drug administration.

For statistical analysis, raw numbers and percentage values were used for descriptive data. Fisher's exact and Wilcoxon tests were used for a comparable analysis of separate groups.

Sensitivity for malignancy detection was calculated.

The result was considered true positive when a malignancy revealed after FNAB or CB was confirmed by surgical resection or other diagnostic procedure such as endobronchial ultrasound-guided biopsy (EBUS), bronchofiberoscopy, or thoracoscopy, or when the pathological result was sufficient for further treatment. The result was considered false negative when biopsy revealed no malignancy, but after surgery or other diagnostic procedure the neoplastic character of the tumour was confirmed.

Negative cases without any further diagnostic work-up or CT control were excluded from the sensitivity calculations.

\section{Results}

\section{Biopsy details}

The average size of punctured lung nodules was $27 \mathrm{~mm}$ and lung infiltration was $41 \mathrm{~mm}(p<0.01)$. In the case of lung tumours, both $\mathrm{CB}$ and $\mathrm{FNAB}$ were performed with comparable frequency rate (214 FNAB vs. $292 \mathrm{CB}$ ), but in the lung infiltration group core biopsy was the preferred technique ( $32 \mathrm{CB}$ vs. 2 FNAB, $p<0.01$ ).

The mean size of mediastinal tumours was $55 \mathrm{~mm}$ and chest wall tumours $44 \mathrm{~mm}$. We did not measure the size of pleural lesions because most of them were widely spread in the entire pleura. Core biopsy was the preferred diagnostic technique in all three groups (MM - 84\%, CWT and PL $-100 \%)$. CT fluoroscopy during core biopsy was widely used in the MM group (in $85 \%$ of procedures) but only occasionally in the CWT and PL groups (20-27\% of procedures).

For the $\mathrm{CB}$ procedures of lung tumours an 18-gauge needle was used most commonly, but in other groups of lesions higher gauge needles were selected.

Biopsy details are summarised in Table 1.

\section{Diagnostic accuracy and pathological outcomes}

Specific pathological diagnosis was confirmed in 447 cases after all 593 procedures. Sensitivity of malignancy diagnosis in the group of lung tumours was $75 \%$ for FNAB and $89.1 \%$ for CB. Sensitivity in other groups, where CB was also the most preferred technique, was counted, respectively, for lung infiltration, mediastinal masses, chest wall tumours, and pleural lesions as $83.3 \%, 90.9 \%, 100 \%$, and $85.7 \%$.

In the group of lung tumours malignancy was confirmed most commonly (79\%), but in the lung infiltra- 
tion group benign process was revealed more frequently (83\%). In the MM and CWT group malignant neoplasm dominated in pathological analysis, but among pleural lesions the rate of malignant and benign processes was comparable.

The most common malignancy in the lung tumour group was adenocarcinoma (135 of 295; 46\%). Among benign nodular lesions, acute or chronic inflammatory process was the most common finding ( 43 of 76 ; 57\%). Interstitial diseases and inflammatory processes were most commonly confirmed in the lung infiltration group (20 of 34; 59\%). Small cell carcinoma and lymphoma dominated among mediastinal pathologies. Metastatic character of chest wall tumours was proven in $88 \%$ cases. In pleural lesions the rate of metastases and benign, fibrotic changes was comparable.

Detailed information about diagnostic accuracy and pathological results is presented in Table 2 and Table 3.

\section{Complications}

In the group of lung tumours pneumothorax was revealed on follow-up X-ray in 71 of 214 (33.2\%) FNABs and 89 of $292(30.5 \%) \mathrm{CBs}$, and there was no statistical difference between these two techniques $(p=0.2)$.

The frequency of chest tube insertion due to pneumothorax was also comparable for each of the techniques $(p=0.9)$ and amounted to $14 \%$ for FNAB and $12.3 \%$ for $\mathrm{CB}$. The frequency of drainage in the lung infiltration group after CB was $12.5 \%$, and it was the same as in the lung tumour group $(p=0.7)$.

The pneumothorax rate in the mediastinal masses group was $23.8 \%$, but drainage was necessary in one case only. In the other two groups pneumothorax was observed occasionally, and it never required further intervention.

Alveolar haemorrhage was commonly seen after procedures performed due to lung tumour and lung infil- tration, and definitely more frequently when core needle was used $(p<0.01)$. Moreover, haemoptysis also was often seen after $\mathrm{CB}$, but only occasionally after FNAB (12.3\% in $\mathrm{CB}$ vs. $1.4 \%$ in FNAB, $p<0.01)$. There was no revealed haemoptysis after procedures performed due to mediastinal mass, chest wall tumour, or pleural lesion.

Complications are listed in Table 4.

\section{Discussion and conclusions}

In chest radiology, behind the large variety of radiological outcomes stands an even greater number of pathological diagnoses. For further treatment it is crucial to differentiate malignant neoplasms from benign processes. In daily practice of many institutions CT-guided percutaneous needle biopsy is still the gold standard of evaluation of chest pathologies $[5,7,8,10]$.

In this study we presented our experience in CT-guided needle biopsies performed due to chest pathologies. In our material we found several significant issues:

1. Core biopsy is a more sensitive technique in lung malignancy detection than fine-needle aspiration biopsy.

2. Core biopsy is a highly accurate technique for evaluation other chest pathologies such as mediastinal masses, chest wall tumours, or pleural lesions.

3. There is no statistical difference between pneumothorax rate and pneumothorax requiring drainage after $\mathrm{CB}$ and FNAB.

4. Haemoptysis was observed more commonly after $\mathrm{CB}$ than after FNAB.

In a meta-analysis Zhang et al. reported that the sensitivity for FNAB varied between $68 \%$ and $95 \%$, and between $84 \%$ and $97 \%$ for CB [8]. A comparison of our results with those from Zhang et al. shows that we obtained similar sensitivity for FNAB and CB in evaluation of lung tumours. We also observed that CT-guided core biopsy is an effective and very safe procedure in the diagnostic field

Table 2. Diagnostic accuracy calculated for all groups of pathologies

\begin{tabular}{|c|c|c|c|c|c|c|}
\hline & \multicolumn{2}{|c|}{ Lung tumours } & \multirow{2}{*}{$\begin{array}{c}\text { Lung } \\
\text { infiltration } \\
\text { CB and FNAB }\end{array}$} & \multirow{2}{*}{$\begin{array}{c}\begin{array}{c}\text { Mediastinal } \\
\text { masses }\end{array} \\
\text { CB and FNAB }\end{array}$} & \multirow{2}{*}{$\begin{array}{c}\begin{array}{c}\text { Chest wall } \\
\text { tumours }\end{array} \\
\text { CB }\end{array}$} & \multirow{2}{*}{$\begin{array}{c}\begin{array}{c}\text { Pleural } \\
\text { lesions }\end{array} \\
\text { CB }\end{array}$} \\
\hline & FNAB & CB & & & & \\
\hline Number of procedures & 214 & 292 & 34 & 25 & 13 & 15 \\
\hline Diagnosis obtained & $131(61.2 \%)$ & $241(82.5 \%)$ & $30(88.2 \%)$ & $21(84.0 \%)$ & $13(100.0 \%)$ & $11(73.3 \%)$ \\
\hline Malignant & $115(53.7 \%)$ & $180(61.6 \%)$ & $5(14.7 \%)$ & $20(80.0 \%)$ & $8(61.5 \%)$ & $6(40.0 \%)$ \\
\hline Benign & $16(7.5 \%)$ & $60(20.5 \%)$ & $25(3.5 \%)$ & $1(4.0 \%)$ & $5(38.5 \%)$ & $5(33.3 \%)$ \\
\hline No diagnosis & $83(38.8 \%)$ & $52(17.8 \%)$ & $4(11.8 \%)$ & $4(16.0 \%)$ & $0(0.0 \%)$ & $4(26.7 \%)$ \\
\hline TP & 114 & 180 & 5 & 20 & 8 & 6 \\
\hline TN & 37 & 55 & 21 & 2 & 3 & 5 \\
\hline Sensitivity & $75.0 \%$ & $89.1 \%$ & $83.3 \%$ & $90.9 \%$ & $100.0 \%$ & $85.7 \%$ \\
\hline Not included in calculation & $25(11.7 \%)$ & $35(10.8 \%)$ & $7(20.6 \%)$ & $1(4.0 \%)$ & $2(15.4 \%)$ & $3(20.0 \%)$ \\
\hline
\end{tabular}

FNAB - fine-needle aspiration biopsy, CB - core biopsy, TP - xxxxxx, TN - xxxxxxx 
Table 3. Specification of pathological findings in all groups of chest pathologies

\begin{tabular}{|c|c|c|c|c|c|c|}
\hline Pathological findings & \multicolumn{2}{|c|}{ Lung tumours } & $\begin{array}{l}\text { Lung } \\
\text { infiltration }\end{array}$ & $\begin{array}{l}\text { Mediastinal } \\
\text { masses }\end{array}$ & $\begin{array}{l}\text { Chest wall } \\
\text { tumours }\end{array}$ & $\begin{array}{l}\text { Pleural } \\
\text { lesions }\end{array}$ \\
\hline Malignant & 115 & 180 & 5 & 20 & 8 & 6 \\
\hline Non-specified NSCLC & $12(10.4 \%)$ & $11(6.1 \%)$ & $0(0.0 \%)$ & $1(5.0 \%)$ & $0(0.0 \%)$ & $0(0.0 \%)$ \\
\hline Adenocarcinoma & $59(51.3 \%)$ & $76(42.2 \%)$ & $3(60.0 \%)$ & $0(0.0 \%)$ & $0(0.0 \%)$ & $0(0.0 \%)$ \\
\hline Carcinoma planoepitheliale & $18(15.7 \%)$ & $43(23.9 \%)$ & $0(0.0 \%)$ & $0(0.0 \%)$ & $0(0.0 \%)$ & $0(0.0 \%)$ \\
\hline Neuroendocrine NSCLC & $3(2.6 \%)$ & $7(3.8 \%)$ & $0(0.0 \%)$ & $0(0.0 \%)$ & $0(0.0 \%)$ & $0(0.0 \%)$ \\
\hline $\mathrm{SCLC}$ & $9(7.8 \%)$ & $4(2.2 \%)$ & $0(0.0 \%)$ & $6(30.0 \%)$ & $0(0.0 \%)$ & $0(0.0 \%)$ \\
\hline Combined NSCLC + SCLC & $5(4.3 \%)$ & $3(1.6 \%)$ & $0(0.0 \%)$ & $0(0.0 \%)$ & $0(0.0 \%)$ & $0(0.0 \%)$ \\
\hline Mesothelioma malignum & $0(0.0 \%)$ & $0(0.0 \%)$ & $0(0.0 \%)$ & $0(0.0 \%)$ & $0(0.0 \%)$ & $1(16.7 \%)$ \\
\hline Metastases & $9(7.8 \%)$ & $30(16.6 \%)$ & $2(40.0 \%)$ & $3(15.0 \%)$ & $7(87.5 \%)$ & $5(83.3 \%)$ \\
\hline Others & $0(0.0 \%)$ & $6(3.3 \%)$ & $0(0.0 \%)$ & $0(0.0 \%)$ & $0(0.0 \%)$ & $0(0.0 \%)$ \\
\hline Sarcoma & $0(0.0 \%)$ & $3(1.9 \%)$ & $0(0.0 \%)$ & $2(10.0 \%)$ & $1(12.5 \%)$ & $0(0.0 \%)$ \\
\hline Thymic cancer & $0(0.0 \%)$ & $0(0.0 \%)$ & $0(0.0 \%)$ & $1(5.0 \%)$ & $0(0.0 \%)$ & $0(0.0 \%)$ \\
\hline Choriocarcinoma & $0(0.0 \%)$ & $0(0.0 \%)$ & $0(0.0 \%)$ & $1(5.0 \%)$ & $0(0.0 \%)$ & $0(0.0 \%)$ \\
\hline Lymphoma & $0(0.0 \%)$ & $3(0.6 \%)$ & $0(0.0 \%)$ & $6(30.0 \%)$ & $0(0.0 \%)$ & $0(0.0 \%)$ \\
\hline Benign & 16 & 60 & 25 & 1 & 5 & 5 \\
\hline Sarcoidosis & $0(0.0 \%)$ & $5(8.3 \%)$ & $2(8.0 \%)$ & $0(0.0 \%)$ & $0(0.0 \%)$ & $0(0.0 \%)$ \\
\hline Tuberculosis & $2(12.5 \%)$ & $6(10 \%)$ & $3(12.0 \%)$ & $0(0.0 \%)$ & $0(0.0 \%)$ & $0(0.0 \%)$ \\
\hline Inflammatory process & $6(37.5 \%)$ & $37(61.7 \%)$ & $10(40.0 \%)$ & $1(100.0 \%)$ & $3(60.0 \%)$ & $0(0.0 \%)$ \\
\hline Interstitial disease & $0(0.0 \%)$ & $3(5 \%)$ & $10(40.0 \%)$ & $0(0.0 \%)$ & $0(0.0 \%)$ & $0(0.0 \%)$ \\
\hline Granulomatosis with polyangiitis & $0(0.0 \%)$ & $3(5 \%)$ & $0(0.0 \%)$ & $0(0.0 \%)$ & $0(0.0 \%)$ & $0(0.0 \%)$ \\
\hline Others & $8(50.0 \%)$ & $6(10 \%)$ & $0(0.0 \%)$ & $0(0.0 \%)$ & $2(40.0 \%)$ & $5(100.0 \%)$ \\
\hline Neurofibroma & $0(0.0 \%)$ & $2(3.8 \%)$ & $0(0.0 \%)$ & $0(0.0 \%)$ & $0(0.0 \%)$ & $0(0.0 \%)$ \\
\hline Hamartoma & $6(37.5 \%)$ & $0(0.0 \%)$ & $0(0.0 \%)$ & $0(0.0 \%)$ & $0(0.0 \%)$ & $0(0.0 \%)$ \\
\hline Fibrotic pleural lesions & $0(0.0 \%)$ & $1(1.9 \%)$ & $0(0.0 \%)$ & $0(0.0 \%)$ & $0(0.0 \%)$ & $5(100.0 \%)$ \\
\hline Pneumoconiosis & $2(12.5 \%)$ & $0(0.0 \%)$ & $0(0.0 \%)$ & $0(0.0 \%)$ & $0(0.0 \%)$ & $0(0.0 \%)$ \\
\hline Rheumatoid nodule & $0(0.0 \%)$ & $0(0.0 \%)$ & $0(0.0 \%)$ & $0(0.0 \%)$ & $0(0.0 \%)$ & $0(0.0 \%)$ \\
\hline Atypical adenomatous hyperplasia & $0(0.0 \%)$ & $3(1.9 \%)$ & $0(0.0 \%)$ & $0(0.0 \%)$ & $0(0.0 \%)$ & $0(0.0 \%)$ \\
\hline
\end{tabular}

NSCLC - non-small cell lung carcer, SCLC - small cell lung cancer

Table 4. Complication after biopsy procedure reported in each group of chest pathologies

\begin{tabular}{|c|c|c|c|c|c|c|c|c|c|c|c|c|c|c|c|c|}
\hline \multirow[t]{2}{*}{ Complications } & \multicolumn{4}{|c|}{ Lung tumours } & \multicolumn{4}{|c|}{ Lung infiltration } & \multicolumn{4}{|c|}{ Mediastinal masses } & \multicolumn{2}{|c|}{$\begin{array}{l}\text { Chest wall } \\
\text { tumours }\end{array}$} & \multicolumn{2}{|c|}{$\begin{array}{l}\text { Pleural } \\
\text { lesions }\end{array}$} \\
\hline & FNAB & 214 & CB & 292 & FNAB & 2 & CB & 32 & FNAB & 4 & CB & 21 & CB & 13 & CB & 15 \\
\hline Pneumothorax & 71 & $33.2 \%$ & 89 & $30.5 \%$ & 1 & $50.0 \%$ & 8 & $25.0 \%$ & 0 & $0.0 \%$ & 5 & $23.8 \%$ & 0 & $0.0 \%$ & 1 & $8.3 \%$ \\
\hline $\begin{array}{l}\text { Pneumothorax without } \\
\text { chest tube insertion }\end{array}$ & 41 & $19.2 \%$ & 53 & $18.2 \%$ & 1 & $50.0 \%$ & 4 & $12.5 \%$ & 0 & $0.0 \%$ & 4 & $19.0 \%$ & 0 & $0.0 \%$ & 1 & $8.3 \%$ \\
\hline $\begin{array}{l}\text { Pneumothorax with } \\
\text { chest tube insertion }\end{array}$ & 30 & $14.0 \%$ & 36 & $12.3 \%$ & 0 & $0.0 \%$ & 4 & $12.5 \%$ & 0 & $0.0 \%$ & 1 & $4.8 \%$ & 0 & $0.0 \%$ & 0 & $0.0 \%$ \\
\hline Alveolar haemorrhage & 62 & $29.0 \%$ & 113 & $38.7 \%$ & 0 & $0.0 \%$ & 10 & $31.3 \%$ & 0 & $0.0 \%$ & 2 & $9.5 \%$ & 0 & $0.0 \%$ & 0 & $0.0 \%$ \\
\hline Haemoptysis & 3 & $1.4 \%$ & 36 & $12.3 \%$ & 0 & $0.0 \%$ & 4 & $12.5 \%$ & 0 & $0.0 \%$ & 0 & $0.0 \%$ & 0 & $0.0 \%$ & 0 & $0.0 \%$ \\
\hline Pleural haematoma & 3 & $1.4 \%$ & 4 & $1.4 \%$ & 0 & $0.0 \%$ & 0 & $0.0 \%$ & 0 & $0.0 \%$ & 0 & $0.0 \%$ & 0 & $0.0 \%$ & 0 & $0.0 \%$ \\
\hline
\end{tabular}

$N A B$ - fine-needle aspiration biopsy, $C B$ - core biopsy 
of other chest pathologies [9]. Other authors also recommended it as the procedure of first choice in the evaluation of mediastinal masses [6], chest wall tumours [7], and pleural lesions [5], obviating more invasive procedures such as thoracoscopy, mediastinoscopy, or thoracotomy.

Heering et al. analysed numerous previous studies according to complication rate, and noted that the pneumothorax rate and pneumothorax with intervention varied greatly (8-50\% and 0-19\%, respectively) [9]. According to their analysis, the pneumothorax rate is strongly connected with the size of the needle, and its rate is higher after $\mathrm{CB}$ procedures. Conversely, the pneumothorax and pneumothorax with intervention rate in our study was similar in each technique used. However, as in the above-mentioned meta-analysis, we found that a thicker needle increased the risk of haemoptysis [9].

\section{Conclusions}

Both FNAB and CB are useful, safe, and sensitive tools, which can be used in chest pathology diagnostic work-up, with acceptably low risk of complications.

\section{Conflict of interest}

The authors report no conflict of interest.

\section{References}

1. Laspas F, Roussakis A, Efthimiadou R, et al. Percutaneous CT-guided fine-needle aspiration of pulmonary lesions: Results and complications in 409 patients. J Med Imaging Radiat Oncol 2008; 52: 458-462.

2. Geraghty PR, Kee ST, McFarlane G, et al. CT-guided transthoracic needle aspiration biopsy of pulmonary nodules: needle size and pneumothorax rate. Radiology 2003; 229: 475-481.

3. Yeow KM, Tsay PK, Cheung YC, et al. Factors affecting diagnostic accuracy of CT-guided coaxial cutting needle lung biopsy: retrospective analysis of 631 procedures. J Vasc Interv Radiol 2003; 14: 581-588.

4. Montaudon M, Latrabe V, Pariente A, et al. Factors influencing accuracy of CT-guided percutaneous biopsies of pulmonary lesions. Eur Radiol 2004; 14: 1234-1240.

5. Azrumelashvili T, Mizandari M, Dundua T. Imaging Guided Percutaneal Core Biopsy Of Pulmonary And Pleural Masses - Technique And Complications. Georgian Med News 2016; 250: 25-33.
6. Petranovic M, Gilman MD, Muniappan A, et al. Diagnostic yield of CT-guided percutaneous transthoracic needle biopsy for diagnosis of anterior mediastinal masses. Am J Roentgenol 2015; 205: 774-779.

7. Azrumelashvili T, Mizandari M, Magalashvili D, et al. Imaging Guided Percutaneal Core Biopsy Of Thoracic Bone And Soft Tissue Lesions - Technique And Complications. Georgian Med News 2016; 250: 17-24.

8. Zhang HF, Zeng XT, Xing F, et al. The diagnostic accuracy of CT-guided percutaneous core needle biopsy and fine needle aspiration in pulmonary lesions: a meta-analysis. Clin Radiol 2016; 71: e1-10.

9. Heerink WJ, de Bock GH, de Jonge GJ, et al. Complication rates of CT-guided transthoracic lung biopsy: meta-analysis. Eur Radiol 2017; 27: 138-148

10. Belfiore G, Di Filippo S, Guida C, et al. CT-guided biopsy of lung lesions. Nucl Med Biol 1994; 21: 713-719. 